Check for updates

NIHR Health and Social Care Workforce Research Unit, Policy Institute, King's College London, London, UK

2 University College London, Royal Free Campus, London, UK

Correspondence to: $\mathrm{S}$ lliffe s.liffe@ucl.ac.uk

Cite this as: BMJ 2021;372:n118 http://dx.doi.org/10.1136/bmj.n118 Published: 18 January 2021

\section{Care homes: averting market failure in a post-covid-19 world}

\author{
We need public and political consensus about long term options \\ Jill Manthorpe, ${ }^{1}$ Steve lliffe ${ }^{2}$
}

Our population is not ageing well. The proportion of older people affected by medium to high disability in England is increasing, but social care cannot meet their needs and seems curiously separate from the NHS. It took a global pandemic for data on care home capacity to be collected weekly and shared with England's regulators and commissioners. ${ }^{1}$

If we assume that half of older people with medium to high disability are cared for in their own homes, by 2025 an additional 71 ooo care home places could be needed. ${ }^{2}$ Some 5500 organisations operate care homes ${ }^{3} ; 90 \%$ of these are private providers, including some charities. The five largest chains in England provide only $15 \%$ of places. Around $70 \%$ of providers have three or fewer care homes. ${ }^{4}$ Most care homes are small enterprises run by owner managers.

\section{Threats to sustainability}

About 3700 care home places (of a total of around 400 0oo) have been lost over the past decade. Many care homes are not accepting residents funded by local authorities because fees cannot cover costs. ${ }^{4}$ Those taking only self-funders are mostly in affluent areas and are likely to remain sustainable and even generate super profits. Local authority payments alone are insufficient to maintain good care homes in good condition. ${ }^{4}$

Sustainability is subject to two further threats. ${ }^{5}$ In homes with mixed funding, self-funders pay more than local authority funded residents, effectively subsidising them. ${ }^{6}$ If self-funders realise this, they may seek fee reductions. Because capital and savings can shrink quickly, some care home residents drop out of self-funding to become local authority funded (payer shift). Local authorities, such as

Worcestershire, are already modelling the effect of payer shift on their budgets. ${ }^{7}$

This matters to the NHS-some of the loudest calls for social care reform come from the health service. ${ }^{8}$ Inequalities in access to social care are increasing, with an estimated 1.5 million older people having an unmet care need. ${ }^{9}$ Limited availability of social care affects hospitals by fostering delayed transfers. ${ }^{10}$ Lack of social care produces excess disability and distress that often presents in primary care. The public is surprised that a fragmented system exists. ${ }^{11}$ While some see the "catastrophic" costs of paying for their own (or parents') care as deeply unfair, most are willing to make some contribution. ${ }^{11}$

\section{Possible solutions}

A tipping point is approaching. ${ }^{12}$ To avoid care home shortages, local authorities need to pay higher fees. This will necessitate public and political consensus about long term options: market management, franchise development, or alternative models of care. Buying out care homes (nationalisation) might stabilise some but would be expensive-the market is worth $€ 17 \mathrm{bn}$ (€19bn; \$23bn). The NHS could enter the care home market, perhaps by promoting a franchise like that underpinning general practice and offer care homes support for training and infrastructure. General practice and care homes are different entities but are community based and focused on local needs. Alternatively, investment in home care, provision of hospital at home, and greater support for family carers might lessen reliance on care homes.

The recent government spending review promised to issue proposals for reform in 2021, adding to the 17 policy documents on social care that have been published since the turn of the century. ${ }^{13}$ In January 2021 the government published a mental health white paper and seems confident that it can get it into legislation in the current parliament. But social care seems stuck on the money questions at a time when connections between care homes and the NHS have never been so important and when there may be more goodwill about sharing budgets than ever before.

Ironically, it may be covid-19 that makes the difference, since it will become increasingly evident that without reform and direction, care quality will continue to deteriorate. Care homes are in the news, and the government should not postpone rational changes to the funding of long term care.

Competing interests: We have read and understood BMJ policy on declaration of interests and have no relevant interests to declare.

Provenance and peer review: Not commissioned; externally peer reviewed.

Care Quality Commission. Joint letter from Care Provider Alliance, Care Quality Commission, Department of Health and Social Care, NHS England and NHS Improvement, 17 Apr 2020. https://content.govdelivery.com/bulletins/gd/UKCQC-286ff51

Kingston A, Wohland P, Wittenberg R, etalCognitive Function and Ageing Studies collaboration. Is late-life dependency increasing or not? A comparison of the cognitive function and ageing studies (CFAS). Lancet 2017;390:1676-84. doi: 10.1016/S0140-6736(17)31575-1 pmid: 28821408

3 Growing old profitably: the struggling care home sector is an unlikely hit with investors. Economist 2018 Nov 10.

https://www.economist.com/britain/2018/11/08/the-struggling-care-homeindustry-is-an-unlikely-hit-with-investors

LaingBuisson. Care homes for older people UK market report. July 2018 https://www.laingbuisson.com/blog/laingbuisson-report-reappraises-thecare-home-capacity-crisis-in-the-light-of-new-data/

LaingBuisson. Care homes for older people UK market report. December 2019. https://www.laingbuisson.com/shop/care-homes-for-older-peopleuk-market-report/

6 Social care: care home market-structure, issues, and cross-subsidisation (England). House of Commons Library briefing paper. 2018. https://commonslibrary.parliament.uk/research-briefings/cbp-8003

NHS Digital. Greater awareness of social care self-funders. 2020. https://digital.nhs.uk/services/social-care-programme/demonstrators-programme-2019-21-case-studies/greater-awareness-of-social-care-self-funders 
8 NHS Providers. NHS Providers joins "Health for Care" coalition for a sustainable social care system. 2019. https://nhsproviders.org/news-blogs/news/nhs-providers-joins-health-for-carecoalition-for-a-sustainable-social-care-system

9 Age UK. Parliamentary briefing social care reform. 2020. https://www.ageuk.org.uk/globalassets/age-uk/documents/reports-and-publications/reports-and-briefings/care-in-crisis/parliamentarybriefing-social-care-reform-july-2020.pdf

10 National Audit Office. Discharging older patients from hospital. 2015. https://www.nao.org.uk/wpcontent/uploads/2015/12/Discharging-older-patients-from-hospital.pdf

11 Rand Corporation. Public acceptability of health and social care funding options for the NHS and social care in the UK. 2019. https://www.rand.org/pubs/externaL_publications/EP67796.html

12 Bottery S, Varrow M, Thorlby R, Wellings D. A fork in the road: next steps for social care funding reform. King's Fund, Health Foundation, 2018.

13 HM Treasury. Spending review. 2020. https:/www.gov.uk/government/publications/spendingreview-2020-documents/spending-review-2020 